\title{
Etnografía y trabajo social: vivencias, perspectivas e intervención
}

\author{
Virginia Romero Plana*
}

\section{Introducción}

Hablar de las ciencias sociales es dialogar sobre un acercamiento a la realidad social, analizar sus estructuras y dinámicas y armar líneas de entendimiento. La antropología aplicada y el trabajo social son dos disciplinas que comparten un interés común: aportan un amplio mundo de soluciones $\mathrm{y}$ alternativas a los problemas del individuo y los grupos sociales.

Dentro de esta misma línea de pensamiento, propósitos e intervención, nace un nuevo vínculo a través de la metodología cualitativa: la etnografía.

En esta reflexión se pretende presentar positivamente al instrumento por excelencia de los antropólogos, la etnografía, como herramienta esencial para los estudios sociales. Estas reflexiones y comentarios no tienen la finalidad de cambiar la metodología del trabajo social, sino todo lo contrario: enriquecerla con nuevas herramientas para escalar niveles en pro del conocimiento de nuestro mundo.

\section{Relaciones y límites}

Las categorías basadas en los fines propuestos por los ámbitos de estudio sirven para organizar logros, metas y líneas de apropiación de la realidad social. Por ello es que hay infinidad de profesiones acogidas bajo cientos de estudios académicos, técnicos o universitarios. Asimismo, el trabajo social busca la participación activa del individuo y de los grupos en la organización, movilización, desarrollo y participación de sus propios recursos y potencialidades, para superar obstáculos en la vida diaria que no permiten un crecimiento óptimo personal y social. También ofrece alternativas de solución que permiten disminuir o erradicar

\footnotetext{
${ }^{*}$ MTC del Departamento de Trabajo Social de la Universidad de Sonora, virgyromero@googlemail.com
}

por completo las distintas situaciones-problema que dominan a la sociedad actual. Por otra parte, la antropología aplicada se centra en el análisis de las esferas de la cultura, haciendo una introspección de las costumbres y estilos de vida propios de las diferentes comunidades. A la vez, se concientiza de la necesidad de transmitir la comprensión y el respeto hacia y por todas las etnias, sistemas sociales y creencias.

El trabajo social, como disciplina enmarcada dentro de las ciencias sociales, ha creado sus límites y ha desarrollado tanto sus líneas de interés, como sus objetos de estudio, sus metodologías y herramientas y su finalidad. La antropología ha hecho lo mismo, siendo, sin embargo, algo más imprecisa en el establecimiento de los límites de los logros a cumplir, ya que el estudio del ser humano y de sus contextos culturales llega a mayor cantidad de propósitos definidos. Así se encuentra cada ámbito con sus determinaciones, y ambas ciencias girando en el cauce de un mismo río, que tiene por logro el conocimiento de los problemas de la sociedad y el establecimiento y desarrollo de recursos y líneas de solución. Ambas estudian el comportamiento de la sociedad, tratando cuestiones inmersas en las estructuras y dinámicas socioeconómicas y culturales, tanto individuales como de un grupo o comunidad.

Aunque el trabajo social está aún relegado al plano de lo cuantitativo, hay que reconocer que la investigación cualitativa, cada vez en mayor medida, quiere involucrar a la disciplina en sus entrañas, para poco a poco tener una perspectiva más amplia de los objetos de estudio. La antropología, en esta relación, podrá enseñarle un gran avance en estas técnicas, en particular con la etnografía.

Pudiera parecer que la antropología peca de distanciamiento frente al objeto de estudio, pero más allá de esta observación hay que resaltar el trato más que amable, respetuoso y tolerante que siempre le regalan a los contextos socioculturales, sea cual sea el horizonte que se esté dimensionando. Al igual que en el trabajo social, la ética en

\section{Savia}




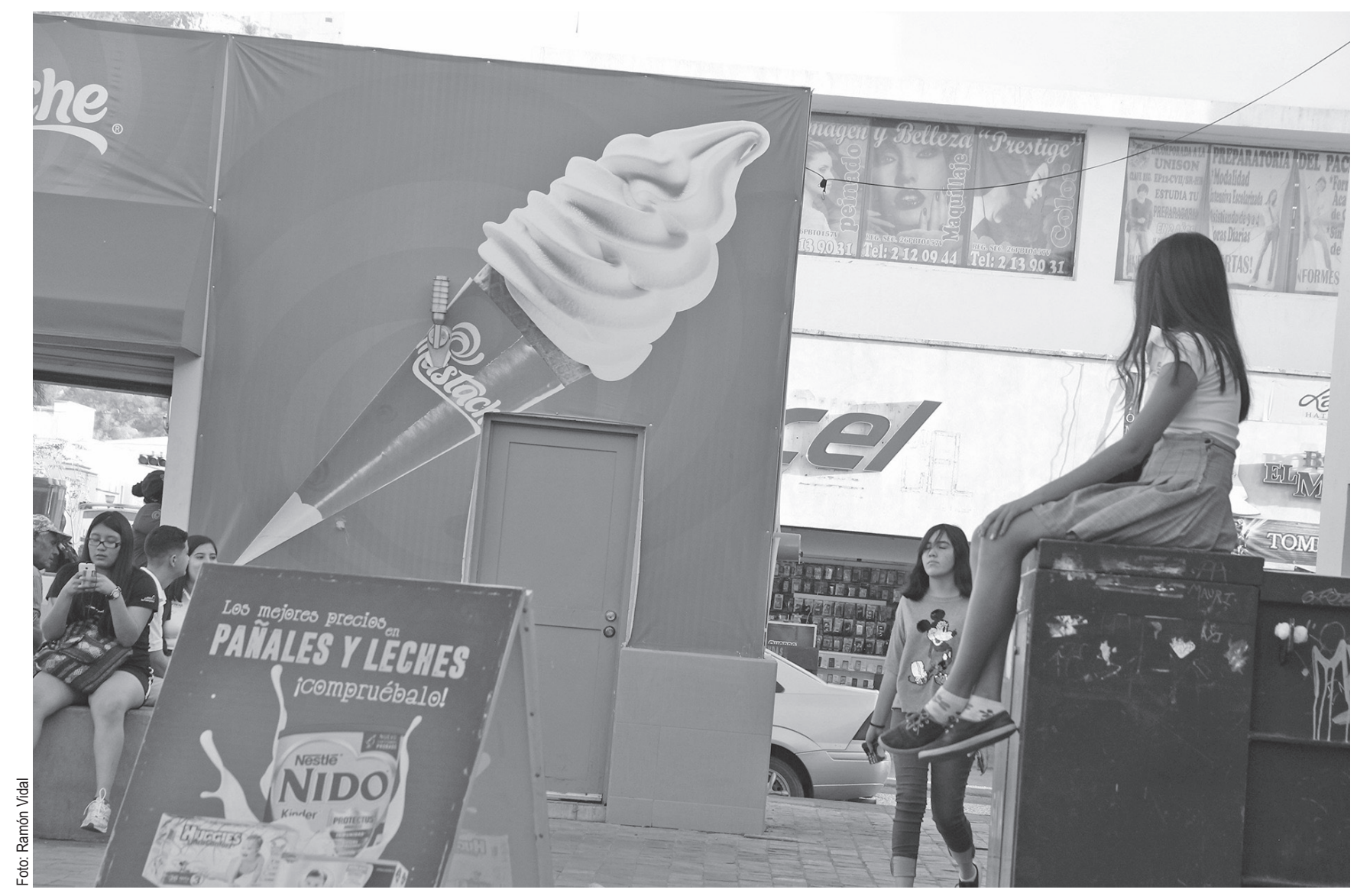

la antropología está asentada desde los primeros estudios, en que no hay posiciones totalmente positivas o negativas, ni mejores ni peores, ni hay tampoco mayores o menores problemas sociales, sino que todo es diferente. Esa lente con la cual debemos observar y acercarnos a la realidad es esencial en la promoción de alternativas o vías de desarrollo.

En este rango no hay que olvidar la importancia de la empatía para el fortalecimiento de estos valores, propios en la persona como ente social y como profesional, derivados de la ética más propia del camino académico de ambas posiciones de vida y entrelazados con la idea de ubicar externamente los juicios de valor y poder acercarse a una comprensión más equilibrada del conocimiento.

Estos puntos en común, relacionados con el carácter de las profesiones y las personas que llevan a cabo dicha labor, ponen de manifiesto un acercamiento a las personas que ayudan a entender la lógica de las dinámicas, relaciones, comportamientos, maneras de pensar, que engloban las mil y una maneras de vivir.

\section{Nuevos tiempos y cambios}

El trabajo social, al igual que las demás disciplinas sociales, va avanzando con el paso del tiempo y moldeándose según los contextos de desarrollo en la práctica profesional y académica. Dicho esto, hay que hacer hincapié en el esfuerzo del gremio social en apuntalar nuevas propuestas que hagan crecer y fortalecer el camino recorrido. La visión tradicional del procedimiento asistencial en gran variedad de temáticas a tratar se ha modificado, haciendo certeros los avances en la parte teórica y metodológica del quehacer. Ese acercamiento a las personas como meros "usuarios" de servicios sociales ha ido mejorando hasta convertirse en una mirada más empática, más igualitaria y más fuerte en las proyecciones futuras.

El positivismo agradeció la confianza depositada por infinidad de estudios que lo tuvieron como único gurú de sus métodos científicos. Nada es estático, y la inestabilidad que aquejó por décadas a este tradicionalismo académico se tornó en una ventana por la que entraba el sol: se vislumbró una luz positiva que equilibró los métodos cuantitativos con los cualitativos.

Los métodos cuantitativos, claves para el paradigma de la perspectiva heredada, son relevantes e interesantes para ciertos estudios de orden estructural y organizacional de la sociedad; pero hay que ampliar esa visión e indagar más dentro de los niveles subjetivos para englobar un conocimiento íntegro de la sociedad y de la perspectiva del individuo como partícipe de determinados contextos socio-culturales (Romero, 2015: 59).

Este renacer de distintas visiones rompió con la idea de que las mediciones de las realidades sociales realmente ayudaban a las intervenciones y a la búsqueda de soluciones. Las estadísticas, aplaudidas por siglos en el estudio de la realidad humana, quedaron relegadas a un plano más secundario (en realidad igualitario) cuando brillan los estudios de corte cualitativo. Estos resultados parciales, ilustrados con números, que además hacían materializarse a las personas y a sus contextos-problema, no satisfacían 
las expectativas de mejora en el trabajo social ni en otros ámbitos de estudio e intervenciones sociales.

En la aproximación cualitativa, las personas se respetan como seres humanos de carne y hueso; en la aproximación cuantitativa, las personas se reducen a cifras y cosas que se suman o restan según convenga. La investigación cualitativa parte de una visión de mundo absolutamente humanista, que no permite la fragmentación de las realidades históricas, ni la atomización de las totalidades sociales; la investigación cuantitativa, por el contrario, parte de una visión de mundo absolutamente tecnocrática, que propicia la cosificación de los hechos sociales, individualizando a las personas y provocando fracturas epistemológicas que impiden recuperar el humanismo negado (Pardo, 1995: 11).

\section{Construcción de realidades culturales diferentes: la etnografía}

La etnografía mayormente ha sido asociada como una de las herramientas clásicas y singulares de la antropología. En algunas acepciones, la etnografía es una de las ramas de la antropología que estudia descriptivamente las culturas. Un antropólogo que nunca haya realizado un estudio etnográfico (de cualquier tema, comunidad o problemática) difícilmente se puede catalogar como tal. Es la práctica más auténtica que la antropología ha brindado a la experiencia y al conocimiento científico de la realidad social.

Una primera idea que se puede aportar para describir qué es la etnografía, es que es una descripción del modo de vida de las personas, de una problemática, de un ritual, de un estilo de vida, de una situación comunitaria, etcétera. A través de esta descripción se halla la comprensión de estructuras sociales, políticas, religiosas y económicas (insertas en las dinámicas, relaciones, costumbres y creencias) que definen al hombre y su cultura. Presentar una imagen "fiel" de la realidad es una de las metas primarias del estudio etnográfico, ya que ella contribuirá por sí sola al entendimiento de ese grupo o de la práctica en cuestión.

Es una herramienta que ha sido criticada por algunos científicos positivistas en tiempos pasados, por su dificultad para objetivar un estudio, para presentar datos reales y por su peculiaridad en el quehacer como tal.

El interés por lo que la gente hace, cómo se comporta, cómo interactúa, cómo construye su vida, cómo la destruye, por qué tiene esas actitudes y un sinfín de cuestiones más, es lo que llevó a la antropología a asentar en su regazo a la etnografía.

Una de las vías de acercarse a la realidad de un problema, en el caso del trabajo social, es tomar los aportes de la etnografía. Para poder crear un buen diagnóstico y una mejor intervención sobre una problemática, es valioso descubrir en qué creen las personas, cuáles son sus valores, qué perspectivas tienen de sus vidas, cuáles son sus reglas de conducta, qué define sus formas de organización, qué roles cumplen los integrantes del grupo, cuáles son sus problemas, qué los motiva, y la forma en cómo se desarrollan y cambian cada uno de los aspectos que caracterizan el día a día de la gente (Woods, 1987).
Los etnógrafos clásicos como Bronislaw Malinowski, Edward E. Evans-Pritchard o Margaret Mead, entre otros, resaltaron el papel fundamental del método etnográfico presentando a la sociedad estudios de tipo analítico y descriptivo acerca de las costumbres, creencias, prácticas sociales y religiosas, conocimientos y comportamientos de una cultura específica.

A través de estas investigaciones se pudieron desarrollar comparaciones culturales y tecnológicas, estudios de carácter cualitativo, estudios de casos, investigaciones de campo, y otros estudios que se caracterizan por la presencia de la observación participante, donde los sujetos estudiados tienen un papel como coinvestigadores. El ambiente natural como elemento preponderante y la ausencia de prejuicios por parte del investigador es algo crucial para el conocimiento (Martínez, 1996). Más allá de todo este conocimiento más objetivo o mayormente categórico con relación a la perspectiva, la etnografía hace trasladar al investigador "a otras maneras de percibir, sentir y reaccionar ante la realidad vivida" (Romero, 2016: 144). Este paso hacia lo cualitativo es lo que está tornando los nuevos estudios hacia una mayor complejidad del proceso de conocimiento humano.

\section{Del romance al conocimiento fortalecido}

Lo que la etnografía ofrece al trabajo social es un sinfín de nuevos planteamientos con relación a los ámbitos abordados desde la disciplina, exploración de factores que integran el problema a través de técnicas para la recolección de información, que no le son ajenas tampoco a su profesión ni a la experiencia: la entrevista en profundidad y la observación participante.

La implicación del trabajador social con el ambiente es fundamental para mantener una línea de intervención en una problemática. Con esta idea no se está argumentando que el trabajador social debe implicarse emocionalmente con todas y cada una de las personas que conforman el contexto, así como con las instituciones o el espacio físico, sino que debe ser capaz de llegar un poco más lejos de una mera descripción. "La observación participante se amiga con la búsqueda de datos a través de la comunicación no verbal. De esas pistas sensoriales e inconscientes, muchas veces, que trasladan a una esfera del conocimiento social, proponiendo ciertos matices para el análisis del material oral" (Romero, 2015: 60).

El entendimiento de las situaciones que se diagnostican como problemas o inconvenientes al desarrollo adecuado de la persona o del grupo, solo es capaz de lograrse en todo su esplendor cuando se accede por la vía de la experiencia. El método etnográfico se basa en la concepción de que todo grupo humano construye, en sus procesos de producción y reproducción, sistemas de significados que estructuran las prácticas culturales del mundo cotidiano (Camacho y Pardo, 1994). Esta experiencia, con la que se acerca uno a la realidad práctica, descentra la visión estereotipada y estática de los espacios culturales, pues atiende a una finalidad de ampliación de miras y perspectivas. El "mundo en el que vivimos" será en ese mismo instante un "minimundo" más

\section{Savia}


de la compleja realidad social, el cual tiene que convivir con muchos otros "minimundos" que conforman nuestros hábitats grupales y nuestra educación y estilos de vida.

La empatía, ese valor que nos inculcan a todos los profesionales sociales, con esta perspectiva crece, llegando a ser el profesional un participante en la cotidianidad del medio social. Es solo alcanzar un nivel más en la apropiación del entorno para comprenderlo más y de maneras múltiples, es alcanzar un modo de entender las situaciones y la manera de percibir a los actores sociales, es generar un mayor grado de ausencia de discriminación y sesgo cultural. Esto último es algo que se ha venido criticando del trabajo social y que hay que reivindicar a través de esta visión más humana, más sensible y, quizá, más práctica.

\section{Breves conclusiones}

La etnografía, a través de todo el bagaje que le ha dado la antropología, pone de manifiesto siempre el importante papel desempeñado por el contexto para llegar a la conducta, la personalidad, las metas, los roles, los valores e interrelaciones adscritas y adquiridas en un sistema social. Se genera una interacción social, y aunque bajo un mismo nivel desde dos posicionamientos diferentes. Esa relación desarrollada de "solo conocimiento", crea un trato para el ser humano de dignidad, respeto, tolerancia y comprensión, que es imprescindible para no solo entender, sino comprender qué quiere la persona o el grupo/comunidad; por qué y cómo lo pretende conseguir; además de las fortalezas y amenazas con las que se cuenta y que hay que considerar en este juego de mejorar los contextos.

La conclusión de esta reflexión es muy sencilla: hay que dar oportunidad a cuantas herramientas, teorías, métodos $\mathrm{y}$ aportes se presenten en el bagaje académico de cualquier disciplina, partiendo de la premisa de que todo aporta, todo enriquece y de todo se aprende.

Se podría decir que la investigación etnográfica no constituye una nueva moda, ni mucho menos una panacea; más bien, es parte de una tradición respetable de estudio que, por diferentes razones históricas, ha quedado durante algún tiempo relegada del enfoque clásico de investigación en varios campos de las ciencias humanas, a los cuales ahora

se está trasladando con plena justicia, con adecuado nivel de rigor y sistematicidad y con grandes promesas para el futuro del conocimiento integral de la sociedad.

\section{Bibliografía}

Camacho, J. y M. Pardo. (1994). Etnografía, episteme y cualidad. Reflexiones, 27, 19-31.

Guba, E. y Y. Lincoln, (2000), Paradigmas en competencia en la investigación cualitativa. En Denman y Haro (comp.). Por los rincones. Antología de métodos cualitativos en la investigación social. México: Colegio de Sonora.

Hammersley, M. y P. Atkinson. (1994). Etnografia. Métodos de investigación. Buenos Aires: Paidós.

Martínez, M. (1986). La capacidad creadora y sus implicaciones para la metodología de la investigación. Psicología (Caracas: UCV), XII, 1-2, 37-62.

Pardo, M. (1995). Ciencia, etnografía y poder. Memorias de la I Jornada de la carrera de Trabajo Social (mayo de 1995), 7-16.

Romero, V. (2015). Historias de vida en contextos de pobreza urbana en Colima: estrategias para afrontar la desigualdad (tesis doctoral presentada el 22 de mayo de 2015). México: Centro de Estudios Superiores e Investigación de Colima.

Romero, V. (2016). Pobreza en Colima. Familias, estrategias e historias de vida. México: Archivo Histórico del Municipio de Colima.

Woods, P. (1987). La escuela por dentro: la etnografia en la investigación educativa. España: Editorial Paidós. 